\title{
RELIABILITY OF THE THORATEC HEARTMATE II FLOW MEASUREMENTS AND ALARMS IN THE PRESENCE OF REDUCED OR NON-EXISTENT FLOW
}

\author{
By \\ Seana G. Hall \\ Copyright (C) Seana G. Hall 2013 \\ A Thesis Submitted to the Faculty of the \\ DEPARTMENT OF MEDICAL PHARMACOLOGY \\ In Partial Fulfillment of the Requirements \\ For the Degree of \\ MASTERS OF SCIENCE \\ In the Graduate College of The \\ UNIVERSITY OF ARIZONA
}

2013 


\section{STATEMENT BY AUTHOR}

This thesis has been submitted in partial fulfillment of requirements for an advanced degree at the University of Arizona and is deposited in the University Library to be made available to borrowers under rules of the Library.

Brief quotations from this thesis are allowable without special permission, provided that an accurate acknowledgement of the source is made. Requests for

permission for extended quotation from or reproduction of this manuscript in whole or in part may be granted by the copyright holder.

SIGNED: Seana G. Hall

\section{APPROVAL BY THESIS DIRECTOR}

This thesis has been approved on the date shown below:

Douglas F. Larson

5/2/2013

Professor of Chemistry

\section{Date}




\section{ACKNOWLEDGEMENTS}

First and foremost, I'd like to thank my primary advisor, Douglas F. Larson, PhD. His enthusiasm for research and continuous education has been inspiring. With his principles in mind, I hope to contribute to research in the field of cardiovascular perfusion throughout the entirety of my career. I am grateful for all of his support throughout the difficult challenge of juggling the full-time pursuit of my Master's, being available to my family throughout this process, and giving me the confidence to believe that I could be successful in all of these endeavors. My accomplishments would not have been possible without him.

I am especially grateful to Richard G. Smith, MSEE CCE for the unique opportunity to be a part of the Artificial Heart Program. He continuously pushed me to seize every opportunity available and greatly furthered my education both in the world of devices as well as perfusion. I know I will continue to apply these lessons throughout the duration of my career.

I would also like to thank Dr. Palmer, MD, Ph.D., for his support and insight during the final stages of my education. He has taught me to forever be compassionate to the individuals and families who put their health in my hands.

Lastly, I would like to thank my family, Willow, and to the love of my life, Jonathan. I owe them all credit for all of my accomplishments in life. I love you all for your endless support. My greatest gratitude goes to my mother, who never wanted me to settle for anything less than extraordinary and adapt and be survivor despite whatever obstacles I may face in life. Your words are forever in my heart and I know you've been by my side for the entirety of this journey. I love you, always. 


\section{TABLE OF CONTENTS}

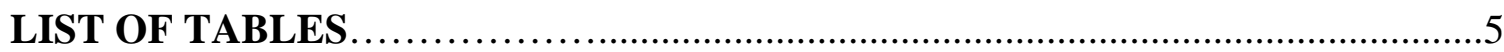

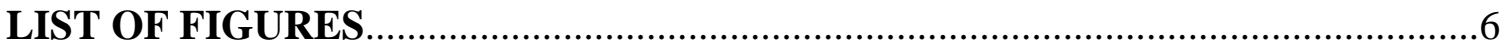

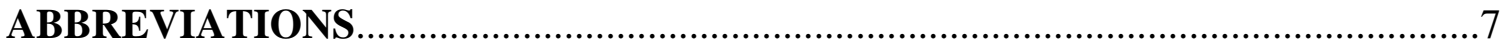

ABSTRACT

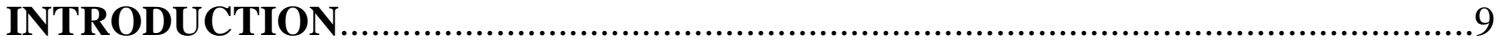

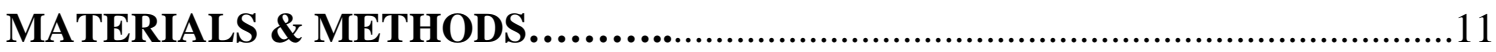

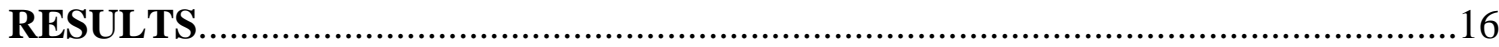

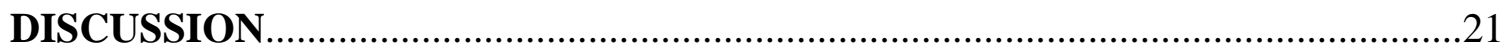

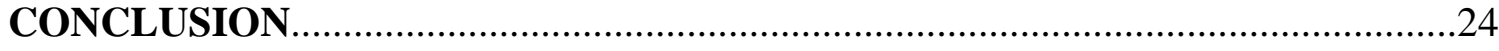

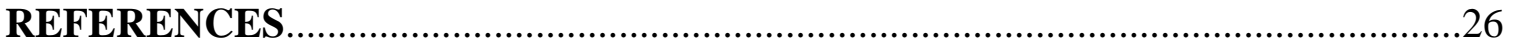




\section{LIST OF TABLES}

Table 1: Syncardia CardioWest and Thoratec HeartMate II Settings............................14

Table 2: Inflow and/or Outflow Occlusions, Hemodynamics, \& Alarms.........................17

Table 3: Hemodynamic Decompensation with a Non-Functioning HeartMate II.............20 


\section{LIST OF FIGURES}

Figure 1: Laboratory Design..................................................................................12

Figure 2: Cardiovascular Simulation Tank.......................................................................13 


\section{ABBREVIATIONS}

\begin{tabular}{ll} 
BP & Blood Pressure \\
CO & Cardiac Output \\
dV & Change in Volume \\
dT & Change in Time \\
HF & Heart Failure \\
HR & Heart Rate \\
LAP & Left Atrial Pressure \\
LVAS & Left Ventricular Assist System \\
MAP & Mean Arterial Blood Pressure \\
MCS & Mechanical Circulatory Support \\
mPAP & Mean Pulmonary Artery Pressure \\
P & Power \\
PAP & Pulmonary Artery Pressure \\
RAP & Right Atrial Pressure \\
RPMs & Rotations Per Minute \\
W & Work \\
\hline
\end{tabular}




\begin{abstract}
The most recognized risk associated with the HeartMate II is thrombosis. In the presence of developing clot, the HeartMate II Display Monitor and System Controller senses a decrease in pump flow and is accompanied by audible and visual alarms when flow rates drop below a certain threshold; however, when flow is completely inhibited, the Display Monitor and System Controller both fail to indicate that flow has reduced to zero and does not produce any corresponding alarms. To test the efficacy of the HeartMate II alarms, the Donavan Mock was used to simulate the hemodynamics of a typical heart failure patient. The hemodynamics were then improved by the addition of the HeartMate II LVAS. Partially occluding the inflow and outflow of the HeartMate II did display changes in flow and presented with alarms when appropriate; however, complete occlusions of the device failed to produce any alarms or accurate changes in flow.
\end{abstract}




\section{INTRODUCTION}

Studies have shown that survival can significantly be prolonged in left ventricular heart failure patients who are supported by the Thoratec HeartMate II LVAS (left ventricular assist system) in comparison to individuals who are only treated by drug therapy or are unable to receive a heart transplant; however, its use has been associated with several reports of technological issues and elevated risk for thrombotic events (1). Defining a universal treatment plan for anticoagulation of HeartMate II recipients continues to be a challenge due to the variability of individuals in response to the same anticoagulation drug therapy (2). Therefore, it is important that clinicians are diligent about evaluating patients for existing thrombotic events. The occurrence of thrombus is typically assessed by aberrations of performance data estimated by the HeartMate II Display Module. Unfortunately, this poses a challenge for the clinician because previous studies have shown this estimation to be unreliable.

Complete pump thrombosis is a rare event; however, there are centers that have well documented this occurrence. The University of British Columbia reported failure of a HeartMate II device due to complete pump thrombosis without any concerning changes in flow, pump power, or RPMs from the HeartMate II Display Module. Thrombosis was suspected based on hemodynamic changes of the patient. It was not until a transesophageal echocardiography was performed that they revealed there was complete blockage of flow through the device due to thrombus (3). Another case study from the University of Virginia College of Medicine examined the occurrence of early post-

implant thrombus formation due to inadequate anticoagulation. Thrombus became 
suspected approximately 2 to 3 weeks post-op with no notable changes in flow, pump power, or RPMs. The patient was identified as having possible pump thrombosis due to hematuria and dyspnea, increasing d-dimers, and rapid hemodynamic decline (4). Unfortunately, in cases such as these, complete occlusion is not detected until the patient begins to show hemodynamic decline and re-emerging symptoms of left ventricular heart failure.

This study hopes to provide a reproducible evaluation of the HeartMate II pump flows and alarms in a controlled laboratory setting with the use of a cardiovascular simulator tank. In this manner, the hemodynamic characteristics of a left ventricular heart failure patient are recreated and subsequently improved with the addition of the Thoratec HeartMate II. By recreating this clinical scenario, perhaps clinicians can come to a better understanding of the mechanism of the Thoratec HeartMate II in order to make a prompt diagnosis of pump thrombosis before patients begin to decompensate and long-term damage ensues. 


\section{MATERIALS AND METHODS}

\section{Laboratory Design}

The experiment was performed with a water-filled Donovan Mock circulation tank, located at the University of Arizona Medical Center's Artificial Heart Department. Seventy-milliliter Syncardia Total Artificial Heart (TAH) ventricles and the CardioWest driver were integrated into the Donovan Mock in order to generate circulation within the system (Figure 1). The simulation tank contained a built in flowmeter to measure the actual flow rates that were generated within the system in addition to the measurements of left cardiac output measured by the CardioWest.

Four chambers exist in the Donovan Mock and represent systemic right atrial pressure, left atrial pressure, pulmonary artery pressure, and aortic pressure. Each chamber was attached to a pressure transducer in order to continuously measure the relative hemodynamic status of each chamber and simultaneously displayed on a hemodynamic Module. Central venous pressure was adjusted within the Mock by adding air to increase chamber pressure simulating an increase in volume and/or systemic pressures. Adversely, pressure was relieved in chambers by opening a valve to release air in order to simulate a decrease in blood volume and/or systemic pressures. The Thoratec HeartMate II was also integrated within the circuit and was connected to the inflow and outflow of the left TAH ventricle (Figure 2). 


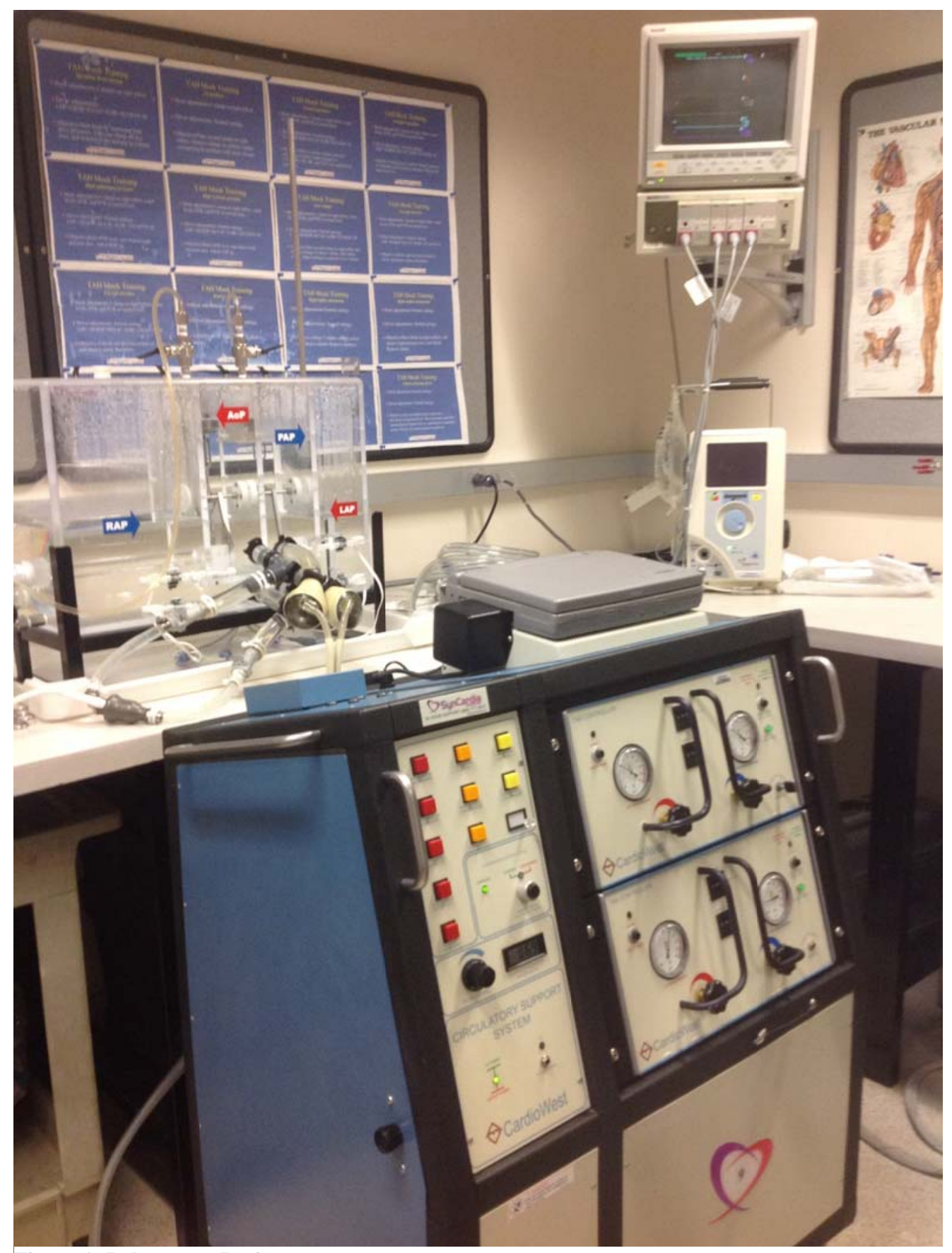

Figure 1: Laboratory Design

The Donovan Mock is a cardiovascular circulatory simulation tank with integrated TAH ventricles powered by the Syncardia CardioWest to provide circulation. Chamber pressures of the Mock are continuously evaluated and its hemodynamic pressures are visible on a Module. 


\section{Creating \& Correcting Heart Failure}

The simulation tank was first adjusted to simulate the healthy hemodynamics of a patient before going into heart failure and replicated multiple times in order to establish reproducibility of the study design. The desired hemodynamics were created by adjusting the settings on the CardioWest, by adjusting the left and right drive pressures, heart rate,

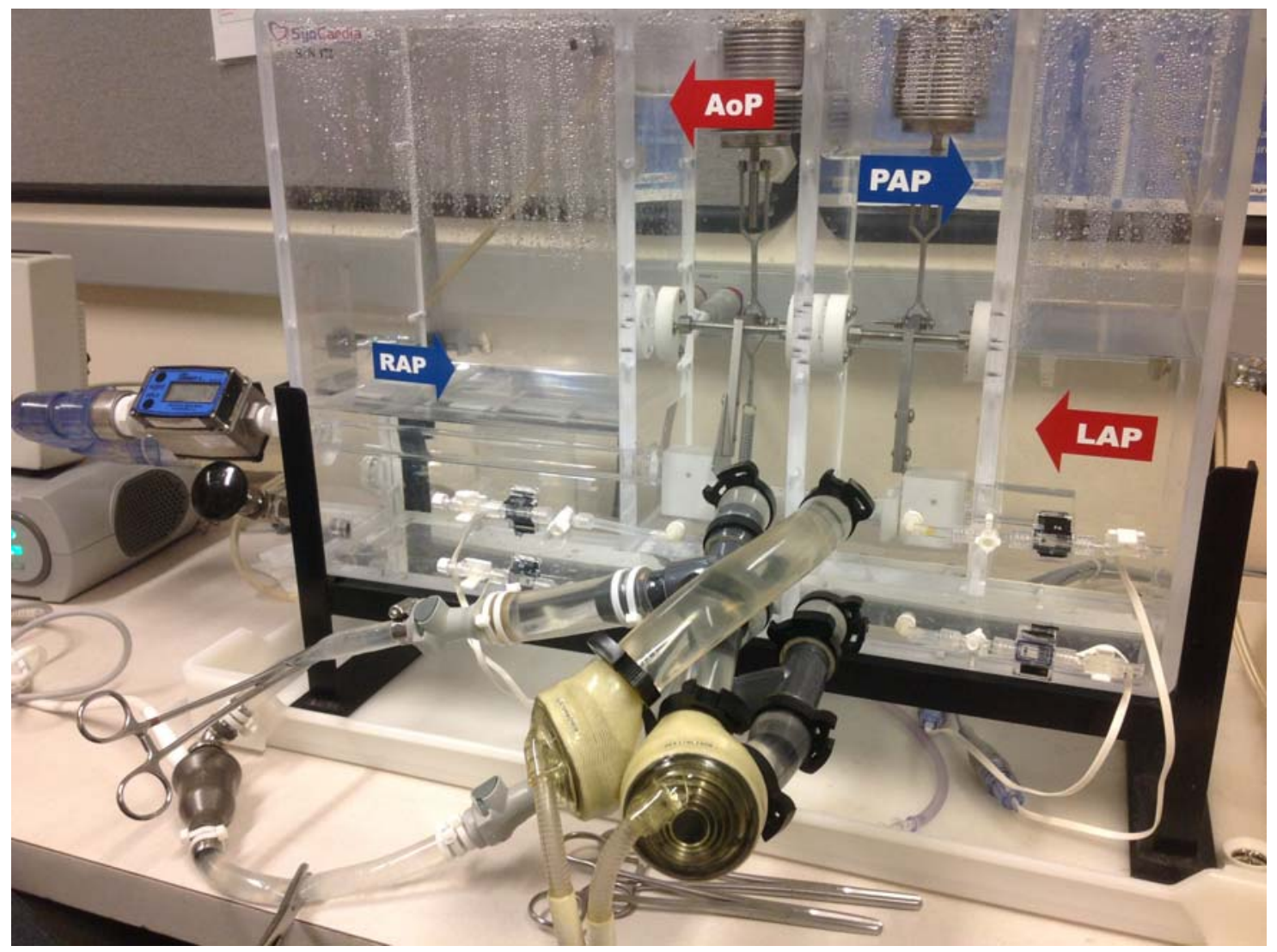

Figure 2: The Donovan Mock

The cardiovascular simulation tank consisted of 4 chambers. These chambers represented the following pressures of the cardiovascular circulatory system: right atrial, left atrial, aortic, and pulmonary artery pressure. Each chamber is connected to a pressure transducer for instantaneous data collection. In addition to the TAH, the Thoratec HeartMate II was also integrated into the system by conduits from the inflow and to the outflow of the left TAH ventricle. 
Table 1: CardioWest and Thoratec HeartMate II Settings

Adjusting the settings of the CardioWest \& HeartMate II LVAS enabled representation of the different patient hemodynamics of a healthy, heart failure, and LVAS-supported individual.

\begin{tabular}{|c|c|c|c|c|}
\hline CardioWest Settings & Healthy & Heart Failure & LVAS Settings & $\begin{array}{l}\text { LVAS } \\
\text { "Implant" }\end{array}$ \\
\hline Heart Rate (BPM) & 125 & 140 & Pump Speed (RPM) & 9800 \\
\hline \% Systole & 50 & 50 & Flow Rate (L/min) & 4.0 \\
\hline Left Drive Pressure (mmHg) & 210 & 90 & Pump Power (W) & 6.2 \\
\hline Right Drive Pressure ( $\mathrm{mmHg}$ ) & 90 & 70 & Pump Index & 3.5 \\
\hline Vacuum $(\mathrm{mmHg})$ & 6 & 4.7 & & \\
\hline Ventricle LCO/RCO (L/min) & $6.2 / 6.9$ & $3.9 / 5.7$ & & \\
\hline Total Mock CO (L/min) & 6.1 & 3.9 & Total Mock CO & 5.2 \\
\hline $\mathrm{BP}(\mathrm{mmHg})$ & $119 / 74(94)$ & $68 / 46(55)$ & BP (mmHg) & $79 / 69(72)$ \\
\hline RAP (mmHg) & 6 & 6 & $\operatorname{RAP}(\mathrm{mmHg})$ & 6 \\
\hline PAP $(\mathrm{mmHg})$ & $23 / 5(13)$ & $32 / 17(23)$ & PAP $(\mathrm{mmHg})$ & 23/7 (14) \\
\hline LAP (mmH) & 10 & 25 & LAP (mmHg) & 13 \\
\hline
\end{tabular}

and vacuum. The left ventricular function was then diminished to simulate heart failure.

The Thoratec HeartMate II LVAS inflow and outflow conduits were then opened to the Mock circulatory system and flow was established and adjusted until the hemodynamics improved (Table 1).

Simulating Thrombus Development

Once the heart failure model's hemodynamics were adequately corrected with the addition of the Thoratec HeartMate II, different occlusions were applied to both the inflow and outflow of the LVAS in order to mimic thrombus. Several combinations of occlusions were evaluated by applying calibrated clamps at different locations on the HeartMate II inflow and outflow tracts, and were also placed at different angles and varying percentages of tubing occlusions. Occlusions were measured at three different percentages of the tubing diameter: $25 \%, 50 \%, 75 \%$, and $100 \%$. Changes in hemodynamics, pump power, and flow, measured by the HeartMate II Display Module, 
CardioWest, and the simulator flowmeter, were all recorded for every occlusion scenario. Any alarms and the time until the alarms occurred were also recorded.

Statistics

Statistical analysis was done using Data Analysis and Statistical Software Stata 11 (StataCorp LP, TX, USA). An independent two-sample t-test was used to identify any significant differences between pump flows as measured by the Thoratec HeartMate II and the pump flow measured from the laboratory simulation tank flow meter. 


\section{RESULTS}

Pump Occlusions and Angles

Thirty-nine different combinations of occlusions were evaluated. Angling of the tubing clamp included perpendicular occlusions to the tubing, and $60^{\circ}$ and $120^{\circ}$ occlusion angles. Varying the angle of the applied occlusion clamp did not affect the efficacy of the alarms occurring when the Display Module detected flow below $2.5 \mathrm{~L} / \mathrm{min}$ and the angles of the clamp did not significantly alter the power required to maintain the device at 9800 RPMs ( $>0.05)$.

Perpendicular occlusions by $25 \%$ of the tubing diameter always corresponded with a decrease in pump power as well as a decrease in flow rate, while RPMs were maintained. Similarly, pump power decreased even more at 50\% occlusion and resulted in decreased flows through the HeartMate II LVAS. RPMs were unaffected. Pump power even decreased further with $75 \%$ occlusion, again correlating with decreases of flow through the device; however, the pump power increased slightly at $100 \%$ occlusion in comparison to $75 \%$ tubing occlusion. The power required to maintain the speed of the HeartMate II was inversely related to the degree of occlusion applied to the inflow and outflow conduits of the device, except for complete occlusion of the tubing, where the Display Module estimated a slight increase in pump power. This increase in pump power, however, is still considerably less than the original pump power measured by the Display Module when no occlusion is present. Due to the variability of pump power and flows, relevant data was primarily analyzed at 50\% occlusions, perpendicular to the inflow and outflow conduits for consistency and reproducibility of the results. 
Table 2: Inflow and/or Outflow Occlusions, Hemodynamics, \& Alarms

A list of occlusions made at a perpendicular $90^{\circ}$ angle and their corresponding alarms, hemodynamics, Display Module measurements, and combined ("Actual CO") and individual outputs of the LVAS and the TAH. Flows and CO are measured as $\mathrm{L} / \mathrm{min}$, power is in the units of Watts, and BP, PAP, LAP, and RAP are in the units of mmHg.

\begin{tabular}{|c|c|c|c|c|c|}
\hline Inflow Clamped Only & $\begin{array}{l}0 \% \\
\text { Occluded }\end{array}$ & $\begin{array}{l}25 \% \\
\text { Occluded }\end{array}$ & 50\% Occluded & 75\% Occluded & $\begin{array}{l}100 \% \\
\text { Occluded }\end{array}$ \\
\hline RPMs & 9800 & 9800 & 9800 & 9800 & 9800 \\
\hline Display Flow & 4.0 & 3.9 & 2.6 & 2.4 & 2.8 \\
\hline Actual LVAS Flow & 4.0 & 3.8 & 2.3 & 1.6 & 0 \\
\hline Pump Power & 6.2 & 6.0 & 5.2 & 5 & 5.3 \\
\hline Pump Index & 3.5 & 3.9 & 3.3 & 3.1 & 2.9 \\
\hline Actual CO & 5.2 & 5.1 & 4.8 & 4.6 & 4.0 \\
\hline BP & $79 / 69(72)$ & $79 / 69(73)$ & $75 / 58(65)$ & $73 / 55(63)$ & $68 / 46(56)$ \\
\hline PAP & $23 / 7(14)$ & $26 / 10(16)$ & $28 / 13$ (19) & $30 / 14(21)$ & $31 / 17(23)$ \\
\hline LAP & 13 & 16 & 20 & 22 & 25 \\
\hline RAP & 8 & 8 & 7 & 7 & 6 \\
\hline Alarms Occurred & None & None & None & "Low Flow" & None \\
\hline Tíme Till Alarm & NA & NA & NA & $\begin{array}{l}11 \mathrm{sec} \text {. until display alarm; } 20 \mathrm{sec} \text {. } \\
\text { until system controller alarm }\end{array}$ & NA \\
\hline $\begin{array}{l}\text { Outflow Clamped } \\
\text { Only }\end{array}$ & $\begin{array}{l}\text { O\% } \\
\text { Occluded }\end{array}$ & $\begin{array}{l}25 \% \\
\text { Occluded }\end{array}$ & 50\% Occluded & $75 \%$ Occluded & $\begin{array}{l}100 \% \\
\text { Occluded }\end{array}$ \\
\hline RPMs & 9800 & 9800 & 9800 & 9800 & 9800 \\
\hline Display Flow & 4.0 & 3.8 & 3.3 & 2.4 & 2.8 \\
\hline Actual LVAS Flow & 4.0 & 3.9 & 3.1 & 2.0 & 0 \\
\hline Pump Power & 6.2 & 6.0 & 5.7 & 5.0 & 5.4 \\
\hline Pump Index & 3.5 & 3.3 & 3.5 & 3.0 & 2.9 \\
\hline Actual Co & 5.2 & 5.1 & 4.9 & 4.7 & 4.3 \\
\hline BP & $79 / 69(72)$ & $79 / 69(73)$ & $77 / 68(68)$ & $75 / 58(65)$ & $68 / 46(56)$ \\
\hline PAP & $23 / 7(14)$ & $26 / 9(16)$ & $25 / 10(16)$ & $28 / 13$ (19) & $32 / 17(23)$ \\
\hline LAP & 13 & 16 & 16 & 20 & 25 \\
\hline RAP & 8 & 8 & 8 & 7 & 6 \\
\hline Alarms Occurred & None & None & None & "Low Flow" & None \\
\hline Time Till Alarm & NA & NA & NA & $\begin{array}{l}11 \mathrm{sec} \text {. until display alarm; } 20 \mathrm{sec} \text {. } \\
\text { until system controller alarm }\end{array}$ & NA \\
\hline $\begin{array}{l}\text { Inflow and Outflow } \\
\text { Clamped }\end{array}$ & $\begin{array}{l}0 \% \\
\text { Occluded }\end{array}$ & $\begin{array}{l}25 \% \\
\text { Occluded }\end{array}$ & $50 \%$ Occluded & $75 \%$ Occluded & $\begin{array}{l}100 \% \\
\text { Occluded }\end{array}$ \\
\hline RPMs & 9800 & 9800 & 9800 & 9800 & 9800 \\
\hline Display Flow & 4.0 & 3.8 & 3.3 & 2.4 & 2.8 \\
\hline Actual LVAS Flow & 4.0 & 3.9 & 3.1 & 2.0 & 0 \\
\hline Pump Power & 6.2 & 6.0 & 5.7 & 5.0 & 5.4 \\
\hline Pump Index & 3.5 & 3.3 & 3.5 & 3.3 & 2.8 \\
\hline Actual CO & 5.2 & 5.1 & 4.7 & 3.0 & 4.0 \\
\hline BP & $79 / 69(72)$ & $79 / 69(73)$ & $74 / 57$ (64) & $63 / 54(62)$ & $68 / 46(56)$ \\
\hline PAP & $23 / 7$ (14) & $26 / 9(16)$ & $28 / 13$ (19) & $30 / 15(21)$ & $32 / 17(23)$ \\
\hline LAP & 13 & 16 & 20 & 22 & 25 \\
\hline RAP & 8 & 8 & 7 & 7 & 6 \\
\hline Alarms Occurred & None & None & "Low Flow" & "Low Flow" & None \\
\hline Time Till Alarm & NA & NA & $\begin{array}{l}16 \text { sec. until } \\
\text { display alarm; } \\
21 \mathrm{sec} \text {. until } \\
\text { system } \\
\text { controller } \\
\text { alarm }\end{array}$ & $\begin{array}{l}9 \mathrm{sec} \text {. until display alarm; } 18 \mathrm{sec} . \\
\text { until system controller alarm }\end{array}$ & NA \\
\hline
\end{tabular}




\section{Evaluation of Flow}

The flows measured by the Display Module did not correlate well to actual cardiac output. Actual pump flows were determined by the difference between total cardiac output measured by the Donovan Mock and left cardiac output measured by the TAH CardioWest. When complete occlusion was placed on the device despite inflow and/or outflow positions, the Display Module always registered a flow of $2.8 \mathrm{~L} / \mathrm{min}$, although zero flow was actually passing through the device. The actual HeartMate II Display Module's flows in the presence of partial occlusion did not correlate well with the actual flows generated by the device $(\mathrm{p}>0.01)$.

In all situations where the HeartMate II Display Module measured a flow less than $2.5 \mathrm{~L} / \mathrm{min}$ in the presence of a partial occlusion on the inflow and/or outflow conduits, the HeartMate II indicated a "Low Flow" alarm on the Display Module. This alarm occurred 10 seconds after the initiation of the occlusion occurred followed a visual red "Broken-Heart" alarm as well as a continuous audible tone by the System Controller occurred at 20 seconds after occlusion. The alarms subsided only once the partial occlusion was removed and flow registered above $2.5 \mathrm{~L} / \mathrm{min}$ on the Thoratec HeartMate II Display Module. Any occlusions that were not enough to drop the flow below 2.5 L/min, according to the Display Module, did not trigger any alarms, despite actual flows being below this value (Table 2). The average difference between actual flow and the Display Module’s calculated flow was $0.4 \mathrm{~L} / \mathrm{min} \pm 0.37 \mathrm{~L} / \mathrm{min}$.

If a growing occlusion was simulated by increasing the percentage of inflow occlusions over time, the alarms only triggered when flow fell below $2.5 \mathrm{~L} / \mathrm{min}$ on the 
Display Module; however, once the occlusion reached 100\% where actual flow through the device was measured as zero, all alarms, both visual and audible, disappeared after 1 second, and a flow of $2.8 \mathrm{~L} / \mathrm{min}$ appeared on the Display Module. 
HeartMate II LVAS Pump Power

Retrograde flow through the HeartMate II was also studied by removing the power supply to the HeartMate II pump and allowing passive flow to occur while the TAH was still functioning at its original heart failure settings. Cardiac output measured by the Donovan Mock decreased from $5.2 \mathrm{~L} / \mathrm{min}$ to $3.7 \mathrm{~L} / \mathrm{min}$. While the CardioWest's left cardiac output and right cardiac output measurements remained unchanged, indicating that the decrease in measured cardiac output by the Donovan Mock would have been a result of retrograde flow through the only other open shunt of the system, being the HeartMate II. This resulted in further decompensation hemodynamic status (Table 3).

Table 3: Hemodynamic Decompensation with a Non-Functioning HeartMate II

If the HeartMate II loses power supply, has a driveline disconnection, or controller failure retrograde flow occurs.

\begin{tabular}{|l|l|l|}
\hline Hemodynamic Status & $\begin{array}{l}\text { Heart Failure with } \\
\text { HeartMate II Support }\end{array}$ & $\begin{array}{l}\text { Non-Functioning } \\
\text { HeartMate II }\end{array}$ \\
\hline Actual CO (L/min) & 5.2 & 3.7 \\
\hline BP (mmHg) & $79 / 69(72)$ & $63 / 49(49)$ \\
\hline PAP (mmHg) & $23 / 7(14)$ & $35 / 24(29)$ \\
LAP (mmHg) & 13 & 31 \\
RAP (mmHs) & 8 & 5
\end{tabular}




\section{DISCUSSION}

In all cases of complete occlusion of the inflow and/or outflow, the Display Module failed to indicate that the flow had dropped to zero. This is due to the algorithm used to calculate the pump flow, since flow is estimated indirectly. Flow is estimated by the measured pump speed $(\mathrm{RPMs})$ and the power $[$ Power $=$ Work/Time] required to maintain the HeartMate II axial pump's RPMs. Flow inaccuracies were also found in the presence of partial or even non-existent occlusions. Pump flows are based on pump power and RPMs of the HeartMate II device; however, flows determined by the Display Module were not consistent with actual flows measured by the flowmeter in Donovan Mock. In a study including 20 patients by Slaughter, et Al., HeartMate II pump flows were directly measured intraoperatively in order to examine flow accuracy utilizing an ultrasonic flow probe on the outside of the device outflow graft. Between flows of 4 to 6 L/minute, which are clinically common operating values, they found a difference of 15$20 \%$ between correct flow and between the Display Module's estimated flow. As a result, they have determined to rely mainly on the trends of the device versus relying on the estimated flow of the Display Module (5).

The human heart will try to maintain flow despite changes in afterload, which may often be detrimental to the function of the heart in cases of chronically elevated afterload, such as heart failure. The axial flow pump in the presence of complete occlusion, however, will still have normal function of its mechanical components and simply rotate against a static volume of fluid caused by complete thrombosis of the pump, while maintaining the RPMs at a normal value without the need to increase work. 
The subtle in pump power from $75 \%$ occlusion to $100 \%$ occlusion may be explained due to the LVAS overcoming an increase in friction. Because RPMs do not change in order to maintain speed, this causes a decrease or complete inhibition of HeartMate II LVAS flow and less work is done to maintain the same speed due to the lack of excess force required to move the fluid. (Axial Pump Work = Force/Distance) (6).

To make things more complicated, the HeartMate II LVAS power decreases in response to increases in resistance, which seems counter-intuitive to clinicians. This is due to their understanding of the mechanics of the human heart, which acts as a volume displacement pump and increases work in the presence of resistance in order to maintain cardiac output $[\mathrm{W}=\mathrm{P} \times \mathrm{dV} / \mathrm{dT}]$. This is evident in the data represented in Table 2, where pump power decreased in the presence of increasing resistance, up until complete occlusion had occurred. This decrease has been thoroughly explained from a fluid mechanics and mathematical perspective in a study by Arnold, et. Al.. The same study also experimentally found that occluding flow into the HeartMate II corresponds with a decrease in pump power (6).

Based on the data collected in this study, the development of a clot that does not completely inhibit the HeartMate II pump is accompanied by decreases in flow outputs as measured by the Display Module; however, if thromboemboli acutely migrated into the device inlet and occluded the flow, this could result in an immediate blockage of flow through the device, without any indication by the Display Module of changes in flow, RPMs, and pump power. Both of these situations have been clinically encountered (7). In this study, gradual occlusion representing growing clot at the inflow of the device 
resulted in continuously decreasing flows as well as presented audible and visual alarms after flows dropped below $2.5 \mathrm{~L} / \mathrm{min}$. Unfortunately, this replication of acute thrombosis formation leading to complete blockage at the inflow of the device, was not accompanied by any significant changes in Display Module power, except for declining hemodynamic changes. Complete inhibition of flow is a life-threatening event that requires immediate treatment, however, it can undetectable to the clinician if they are looking at the Display Module data alone. 


\section{CONCLUSION}

Pump thrombus occurs in 2-3\% of the recipients; however, complete replacement of the HeartMate II LVAS and has been associated with low mortality rates (8). This solution is costly to the patient, but provides complete certainty that the thrombus has been removed. Other studies have shown that the use of eptifibatide can be effective at treating thrombosis non-surgically (9). Despite the route of treatment, intervening in a timely manner may prevent extensive end-organ damage due to the reestablishment of decompensated left ventricular heart failure. Further research should be dedicated to detecting pump thrombosis pro-actively so that treatment can be given as soon as possible.

The algorithm used to calculate flow generated by the HeartMate II is solely solely an estimation. Although this estimation may sometimes be within range of true device output, it is best to use it clinically as an evaluation of flow trends over time. If hemodynamics in a HeartMate II recipient begin to decline, the device may need to be examined for possible thrombosis, or needs to have a clinician increase or decrease its RPMs. Unfortunately, it can be difficult to distinguish between inadequacies of the device versus treatment that may directly be needed by the patient. Changes should not be made to compensate for issues that require an alteration in medical and pharmacological management of the patient, such as hyper- or hypovolemia, hypertension, pulmonary hypertension, or right-sided heart failure. Further research is required in order to determine a more accurate marker for thrombus. This may include regular assessment of hemolysis that are often associated with pump thrombus, especially 
in outpatient patients who are coming into the clinic for follow up. This may help clinicians detect thrombus, partial or complete, before heart failure symptoms reappear; however, the only reliable measurement of flow through the device today is through transesophageal echocardiography or right heart catheterization (9).

Clinicians often use pump power to detect thrombotic events in the HeartMate II; however, it is important that the clinician remain cognizant of the different mechanisms of the native heart versus an axial flow pump. This is rather challenging since the HeartMate II decreases power in response to increases in resistance, which is counterintuitive to clinicians who are used to the opposite being true for the native heart. Although pump power may not seem significantly higher, flow may appear as generally unchanged or within acceptable limits when there is complete blockage of flow through the device. Complete thrombosis is a life-threatening situation and requires immediate medical intervention. The clinician should be attentive not only to the trends of the device, but also always be aware of any physiological or symptomatic changes in the patient, especially if they are portraying signs of left ventricular heart failure.

\section{DISCLOSURE}

No financial funding was provided for the following study. 


\section{REFERENCES}

1. Sheikh FH, Russell SD. HeartMate ${ }^{\circledR}$ II continuous-flow left ventricular assist system. Expert Rev Med Devices 2011, Jan;8(1):11-21.

2. Rossi M, Serraino GF, Jiritano F, Renzulli A. What is the optimal anticoagulation in patients with a left ventricular assist device? Interact Cardiovasc Thorac Surg 2012, Oct;15(4):733-40.

3. Bashir J, Cheung A, Kaan A, Kearns M, Ibey A, Ignaszewski A. Thrombosis and failure of a heartmate II device in the absence of alarms. J Heart Lung Transplant 2011, Oct;30(10):1197-9.

4. Bhamidipati CM, Ailawadi G, Bergin J, Kern JA. Early thrombus in a heartmate II left ventricular assist device: A potential cause of hemolysis and diagnostic dilemma. $\mathrm{J}$ Thorac Cardiovasc Surg 2010, Jul;140(1):e7-8.

5. Slaughter MS, Bartoli CR, Sobieski MA, Pantalos GM, Giridharan GA, Dowling RD, et al. Intraoperative evaluation of the heartmate II flow estimator. J Heart Lung Transplant 2009, Jan;28(1):39-43.

6. Arnold WS, Bourque K. The engineer and the clinician: Understanding the work output and troubleshooting of the heartmate II rotary flow pump. J Thorac Cardiovasc Surg 2013, Jan;145(1):32-6.7.

7. Moazami N, Milano CA, John R, Sun B, Adamson RM, Pagani FD, et al. Pump replacement for left ventricular assist device failure can be done safely and is associated with low mortality. Ann Thorac Surg 2013, Feb;95(2):500-5. 
8. Bhamidipati CM, Ailawadi G, Bergin J, Kern JA. Early thrombus in a heartmate II left ventricular assist device: A potential cause of hemolysis and diagnostic dilemma. J Thorac Cardiovasc Surg 2010, Jul;140(1):e7-8.

9. Jennings DL, Cabrera R, Wang DD, Tita C. Successful treatment of a continuous flow left ventricular assist device thrombosis with eptifibatide. ASAIO J 2012;58(6):633-5. 